\title{
Effect of power grid tariffs on demand-side management in all-electric buildings in Norway
}

\author{
Sophie Schönfeldt Karlsen ${ }^{1}$, Stian Backe ${ }^{2}$, Mohamed Hamdy ${ }^{1 *}$ \\ ${ }^{1}$ Norwegian University of Science and Technology, \\ Department of Civil and Environmental Engineering, Trondheim, Norway \\ ${ }^{2}$ Norwegian University of Science and Technology, \\ Department of Industrial Economics and Technology Management, Trondheim, Norway \\ *Corresponding author: mohamed.hamdy@ntnu.no
}

\begin{abstract}
Power load variations due to more variable renewable energy and electrification can be partly dealt with by controlling flexible loads in buildings (i.e. demandside management (DSM)). This paper evaluates four different grid tariff schemes, and how they affect the value of DSM in buildings where heating and appliances are all powered by electricity. Incentives for DSM through increased energy efficiency and load shifting provided by the tariff schemes are investigated. Our analysis is based on simulation for a single family house in Norway in 96 cases. Results show that load shifting enable lower bills for consumers increasing energy efficiency.
\end{abstract}

\section{Introduction}

The EU has an objective of removing 95-99\% of greenhouse gas emissions in the power sector by 2050 compared to 1990 (EU (2011)). This will require large scale integration of variable renewable energy (like solar and wind), and it will affect future power grid investments and the value of flexible resources in the power sector. One category of flexible resources are known as demand-side management (DSM), which is 'a portfolio of measures to improve the energy system at the side of consumption' (Palensky and Dietrich (2011)). Building developers can have a valuable role in future power systems by using energy storage capacity and demand response in the building stock (De Groote and Fabbri (2016)). New tariff schemes enabled through advanced metering infrastructure (AMI) (Ipakchi and Albuyeh (2009)) could provide savings in peaking infrastructure worth up to $€ 67$ billion in the EU (Faruqui et al. (2010)).

The electricity bill in Norway consists of three parts: (1) energy, (2) grid and (3) taxes \& levies (Eurelectric (2014)), where the grid part usually makes up the highest share (see Figure 1). The Norwegian Water Resources and Energy Directorate (NVE) regulates billing of the grid part. In Hansen et al. (2017), NVE evaluates three new dynamic grid tariff schemes as candidates to be introduced in Norway from 2021. Hearing respondents point out that the tariff schemes

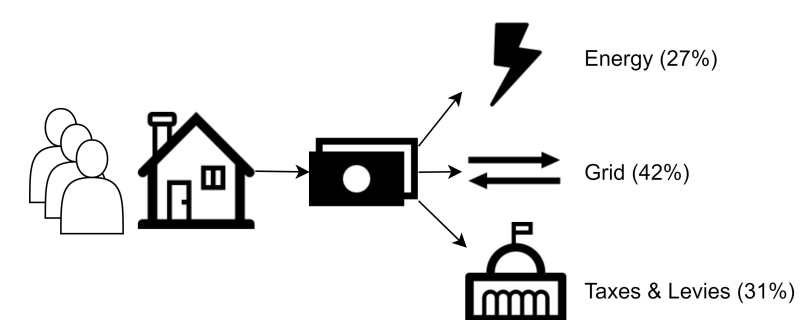

Figure 1: The grid part makes up the highest share for households in Norway (Eurelectric (2014)).

have not been researched enough, and that there is a need to know what kind of impact the suggested tariffs will have.

This paper analyzes how household customers in single family houses in Norway are affected by different grid tariff schemes, and how they can reduce their costs by linking increased energy efficiency measures with load shifting. The load profiles for the single family houses are generated using the simulation software IDA ICE based on a reference house in Norway.

We investigate 96 cases and 6 varying parameters related to building envelope, electric heating system, electric and thermal solar energy production, electric vehicle $(\mathrm{EV})$ charging and window openings. We compare the three new grid tariff schemes suggested by NVE in Hansen et al. (2017) and today's energybased scheme in Norway for the 96 cases using an algorithm developed and implemented in Microsoft Excel to (1) investigate costs related to different grid tariff schemes and energy efficiency measures and (2) to calculate cost savings through load shifting. We examine the only possible load shifting strategy as altering space heating (SH) loads. Our contribution is to deepen the understanding of how different grid tariff schemes provide end-users with incentives for (1) increasing energy efficiency and (2) performing load shifting of SH loads to save costs.

\section{Background}

International research has been done on how buildings can play an active role in the power system through DSM and reaction to price signals.

In Faruqui and Sergici (2010), 15 experiments on dif- 
ferent dynamic pricing schemes in residential houses investigate whether households will respond to price signals. The results show that price signals lead to a significant reduction in consumption during peak demand periods, and infrequent high peak prices (critical peak pricing $(\mathrm{CPP})$ ) are more effective at reducing peaks than static penalty hours (time-of-use pricing $(\mathrm{ToU}))$. This analysis compares different pricing schemes in different experiments, but does not compare the pricing schemes for a common data set.

In AboGaleela et al. (2012), a model maximizing load factor and minimizing energy costs through DSM measures have been developed. The case study analyses load shifting when prices vary between four levels throughout the day. The results show that load shifting can both increase the load factor on the grid and save costs for consumers. The analysis does not consider different pricing schemes.

In Schreiber et al. (2015), the impact of different grid tariffs on three different households are investigated. The study finds that peak demands are reduced with power-based grid tariff schemes, and that a tariff scheme based on a penalty charge when load exceeds a subscription limit provides most robust peak shaving. They also find that a big variation in spot price of electricity can reduce the incentive to shave peaks due to arbitrage possibilities. The study only considers buildings with or without PV and DSM devices.

In Fridgen et al. (2018), 12 net purchase and sale tariff schemes are investigated and their effect on microgrids. They found that fully volumetric billing (based only on price per $\mathrm{kWh}$ ) can induce high load peaks and encourages customers to minimize their grid interaction. They also found that power-based tariff schemes combined with fixed charges are favourable to reduce peak load from microgrids, and they suggest negotiation of such rates since customers contribute with different load and generation profiles.

In summary, previous research indicate that different pricing schemes for electricity in buildings affect incentives and resulting strategies for DSM, however, linking energy efficiency measures at the residential scale with cost savings related to load shifting is poorly studied. This paper evaluates how measures to increase energy efficiency in all-electric buildings will affect savings under four different pricing schemes and the resulting load shifting strategies.

\section{Method}

\section{Grid tariff schemes}

The four different grid tariff schemes discussed by NVE in Hansen et al. (2017) are considered in this work. Two tariff schemes, the energy rate (ER) scheme and the time-of-use (ToU) scheme, are energybased schemes where the cost calculation is purely based on how much (and when) energy is consumed during the billing period. The other two tariff
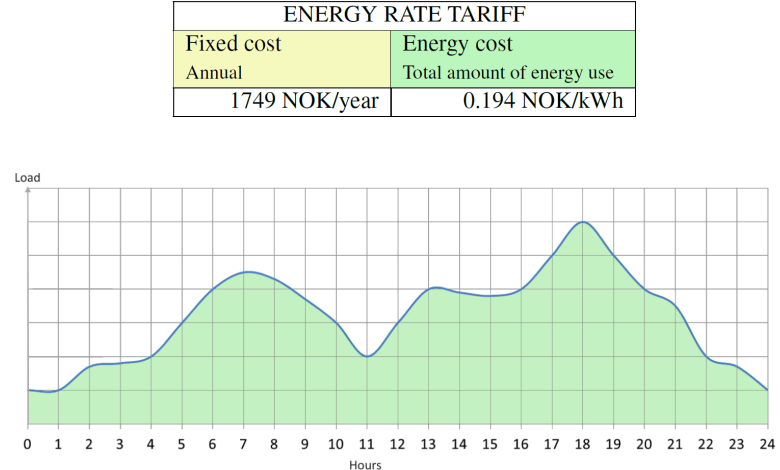

Figure 2: The energy-based (ER) tariff scheme where only energy has a fixed cost per $k W h$ (green area).

schemes, measured power (MP) scheme and tiered rate (TR) scheme, are power-based tariff schemes where the cost calculation is mostly based on the power outtake during the billing period. The suggested rates for each grid tariff scheme is based on Norwegian tariff rates from 2017 and are given in NOK. The rates are calculated in Hansen et al. (2017) to keep the minimum cost equal for all tariff schemes and the income to the grid company constant based on data set of 500 hourly load profiles from Norway for one year (assuming no changes in the customer load profiles).

The current grid tariff scheme in Norway is an energybased (ER) scheme consisting of two parts: One part is a fixed annual cost equal for all customers and the other is an energy cost based on the individual customers energy consumption (see Figure 2). A drawback of the ER scheme is that there is no penalty cost related to high loads.

In the time-of-use (ToU) scheme, some hours have higher energy price than others (see Figure 3 ). The hours with high pricing are the hours with historically high loads. For Norway, the ToU scheme is suggested to have a higher price during winter, especially in daytime, as these have been the critical hours for stress on the grid. The model is easy to communicate to the customer and easy for the customers to plan and react to as the pricing is attached to fixed hours. A drawback of this model is that the income will rely on consumption that depend on the outside temperature, which vary largely from year to year.

The measured power (MP) scheme consist of three parts: A fixed part, an energy part and a power part (see Figure 4). The power part is based on the highest load averaged over an hour $(\mathrm{kWh} / \mathrm{h})$ during the measuring period. Note that there is only one hour during the measuring period making up the costs, and the hour with the highest load cannot be known in advance. We assume a measuring period of 24 hours, which means there is a new opportunity to save costs by shaving the highest load every day. Large industrial customers in Norway are subject to the MP scheme, however, the measuring period can be up to 

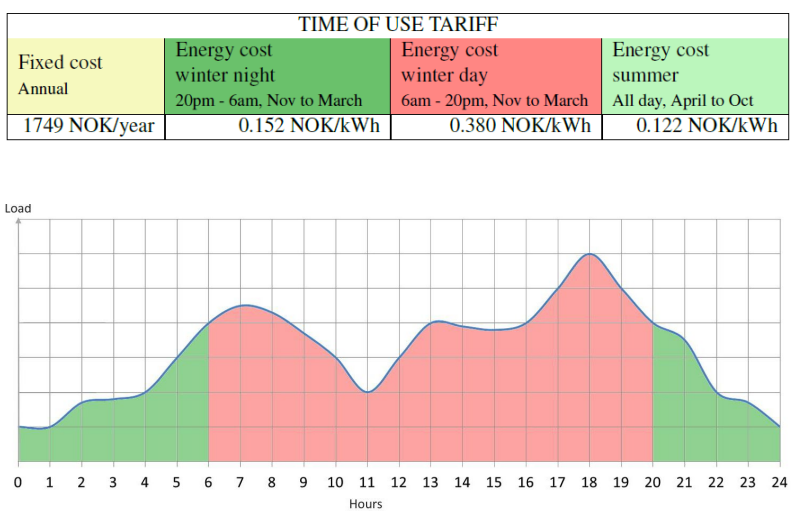

Figure 3: The time-of-use (ToU) tariff scheme where energy has a cost per $k W h$ depending on season and hour. The figure shows a winter day (green area is billed with night rate and red area with day rate).

\begin{tabular}{|c|c|c|}
\hline \multicolumn{3}{|c|}{ MEASURED POWER RATE TARIFF } \\
\hline $\begin{array}{l}\text { Fixed cost } \\
\text { Annual }\end{array}$ & $\begin{array}{l}\text { Energy cost } \\
\text { Total amount of energy use }\end{array}$ & $\begin{array}{l}\text { Measured power cost } \\
\text { Highest peak daily }\end{array}$ \\
\hline 1749 NOK/year & $0.050 \mathrm{NOK} / \mathrm{kWh}$ & $1.86 \mathrm{NOK} / \mathrm{kWh} / \mathrm{h}$ \\
\hline
\end{tabular}

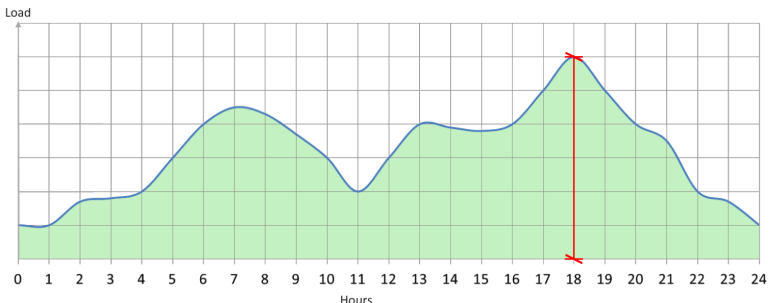

Figure 4: The measured power (MP) tariff scheme where energy has a small cost per $k W h$ (green area) and the highest measured power outtake (red line) is billed additionally.

12 months for industrial customers making it hard to react to. The cost for the energy part is based on the marginal loss rate. Drawbacks of this model is that customers may be charged for high loads at times when the grid has good capacity. The longer the measuring period, the smaller is the probability for coincidence between peak demand for the customer and the grid. Also, if a peak has already occurred in the measuring period, the customer can continue to induce high loads within the size of the penalty peak without extra charge.

In the tiered rate (TR) scheme, the customer pays an overuse cost if their load is above a set limit. This tariff consist of four parts: One fixed part, one subscription part (annually fixed), an energy part and an overuse part (see Figure 5). As the overuse part of the tariff is accounting for all hours and loads that are above the subscription limit, one hour of overuse will not lessen the customers economical incentive to avoid overuse at later hours. We assume 10 choices of limits ranging from 1 to $10 \mathrm{kWh} / \mathrm{h}$ that are fixed for one year. If the limit is set too high, the subscription cost will be higher than necessary. Like the MP scheme, the cost of the energy part is set to the marginal loss rate. Drawbacks with the TR scheme is that customer loads at hours with good capacity
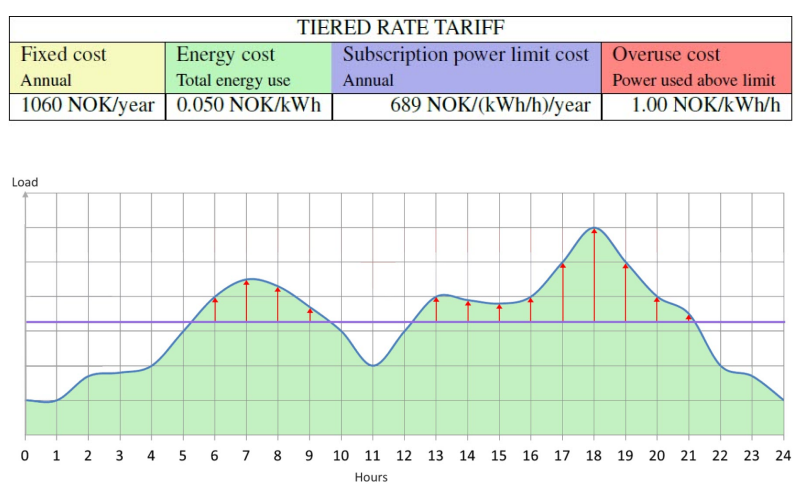

Figure 5: The tiered rate (TR) tariff scheme where energy has a small cost per $k W h$ (green area) and power outtake (red lines) above a subscribed limit (purple line) is billed additionally.

on the grid will be charged overuse cost. If these customers adjust their demand to avoid the overuse cost it will have no value to the grid, and it represents a socioeconomic loss. Also, if customers reduce their loads to the subscribed limit, there is no incentive to reduce it further.

\section{Generating demand profiles}

A reference model in IDA ICE developed by Hagen (2018) for a single family house has been constructed according to the technical requirements in TEK17 (DiBK (2017)) representing the current minimum technical requirements for new buildings in Norway. The house consist of two floors with a total floor area of $149.46 \mathrm{~m}^{2}$, and is built on flat ground with no basement. The building is assumed to be in a suburban area in Oslo. Realistic schedules for light, equipment and domestic hot water (DHW) inspired by the technical specification SN/TS 3031:2016 is used.

Table 1 presents the different parameters investigated in the simulation. Our parameters are linked to the building envelope, user behaviour and relevant technologies. Air source heat pumps (ASHP), solar thermal collectors (STC) and photovoltaic (PV) panels are all examples of building-integrated energy supply technologies that are becoming relevant parts of a building's energy system. We have also considered charging of EVs.

Two different kinds of building envelopes have been compared: one representing new buildings and one representing the old building stock. The new building is constructed according to the requirements in TEK17. The old building is based on the same model, but with insulation and windows equal to a typical building from the '60s. It is of interest to investigate the cost for each grid tariff scheme for buildings of different age to understand the incentives provided to perform deep renovation of old buildings.

The two heating systems evaluated are a direct electric heating system and an indirect heating source in the form of an air source heat pump (ASHP). The direct electric heating system has a $\mathrm{COP}$ equal to 
Table 1: Building aspects and varying parameters to simulate 96 load profiles for a residential house.

\begin{tabular}{|c|c|}
\hline Aspect & Parameter \\
\hline Building & TEK17 standard \\
Envelope & '60s standard \\
\hline Heating & Direct electric heating \\
System & Air source heat pump (ASHP) \\
\hline Solar Thermal & Without STC \\
Collector (STC) & With STC \\
\hline Photovoltaic & Without PV \\
Panels (PV) & With PV \\
\hline Window & Temperature controlled (TCO) \\
openings & Occupant controlled (OCO) \\
\hline Electric & Without EV \\
Vehicle & EV, typical charging \\
(EV) & EV, delayed charging \\
\hline
\end{tabular}

1 , which means that the supply power is equal to the delivered heating to the space. The ASHP is based on the power values and COP from the Toshiba Heat Pump Daiseikai 9 RAS-35 with a COP of 2.41 at $-7^{\circ} \mathrm{C}$. We assume the power output and COP of the ASHP to be linearly dependant on the outdoor temperature. The outdoor temperature is taken from hourly weather data for Oslo, Gardermoen. The minimum COP for the ASHP is equal to 1.

The PV is assumed to be placed on the roof of the building with the optimal angles to obtain the highest gain. Default values for PV in IDA ICE are used, and the overall efficiency is set to 0.15 . Production by $\mathrm{PV}$ is estimated to be $5,152 \mathrm{kWh} /$ year. We assume net metering policy on the residual load profile with PV, i.e. production and consumption is metered together (residual load is consumption minus production). If the PV are producing surplus electricity (i.e. the house is not self-consuming and the residual load is negative), we assume excess energy is sold at a flat price of $0.29 \mathrm{NOK} / \mathrm{kWh}$ based on the average spot price in Norway in 2017 from Nord Pool historical market data and compensation for avoided grid losses based on Norwegian standard contracts.

The STC is connected to a DHW tank and assumed to be $6 \mathrm{~m}^{2}$. Default values for a flat plated STC in IDA ICE is used. The STC is able to gain some heat even during winter. When there is not enough heat gained through the STC, we assume the DHW demand is met through electric heating with a COP of 1 . The STC is estimated to reduce the DHW demand with $1,718 \mathrm{kWh} /$ year.

Two different window opening schedules were simulated: Temperature controlled openings (TCO) and occupant controlled openings (OCO). With TCO, the windows open when the temperatures gets higher than the set point value for cooling $\left(24^{\circ} \mathrm{C}\right)$ and the heating system is turned off. In the case of OCO, occupants keep windows open without turning off the heating system when the temperature is above the set point for heating $\left(20^{\circ} \mathrm{C}\right.$ at night and $22^{\circ} \mathrm{C}$ dur- ing day). The OCO is typically motivated by the desire to ventilate or keeping a cool temperature at night. With the OCO, bedroom windows are consistently open during the night ( 8 hours), while other windows are open during weekday evenings ( 7 hours) or weekend days (16 hours).

EVs can increase the evening peak loads of households as they are normally charging in the afternoon (Lopes et al. (2011)). In this study, we compare an early afternoon charging schedule and a delayed charging schedule (after the afternoon grid peak). We assume battery size of $31.5 \mathrm{kWh}$ inspired by Volkswagen eGolf and home charging station able to fully charge the car in approximately 11 hours. The EV is assumed to use $80 \%$ of maximum capacity every day, so we assume 9 hours of charging is needed on a daily basis. Typical charging starts at 16:00 (when people come home from work) and delayed charging starts at 21:00 (5 hours delay).

\section{Load shifting}

The contribution of this work is to investigate how changing the energy efficiency parameters presented above affect the potential to perform load shifting and save costs for different pricing schemes.

Potential flexible loads for single familiy houses include the use of appliances (e.g. washing machines, dryers and dishwashers), charging of EVs and controlling SH and DHW heating (Gottwalt et al. (2011)).

Running washing machines, dryers and dishwashers during off-peak periods often means running them at night or when people are not home. This includes a risk of fire. The total energy demand of appliances is also rather small compared to other residential loads (heat and lighting), so we do not consider load shifting of appliances. We do consider shifting charging loads for EVs, specifically delayed charging to avoid the evening load peak.

As heating of buildings is the largest part of the energy consumption in buildings, and also the reason for the critical load peaks during winter in Norway, shifting of the heat load has been specifically surveyed for all cases. We only investigate shifting of SH (not DHW). Ideal load shift is a theoretical optimal amount of load shifted to obtain the lowest cost according to the tariff scheme. Ideal load shift is evaluated for each grid tariff scheme to quantify amount and duration of load shift.

Assumptions made in our calculations for the potential to load shift are the following: (1) All SH load can be shifted within 24 hours and (2) there are no losses related to load shifting. SH demand can thus be extracted as a daily energy demand that can be met with any load profile adjusted in favor of the considered grid tariff scheme. Storage possibilities include utilizing thermal mass (walls and floors) in the building envelope and, since we assume an all-electric 


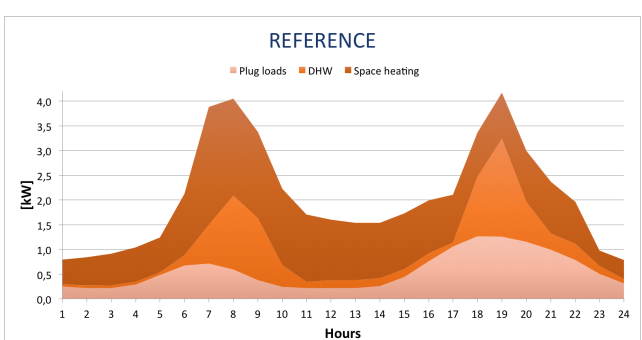

Figure 6: Typical residential load profile without load shifting (cost-optimal under the ER scheme).

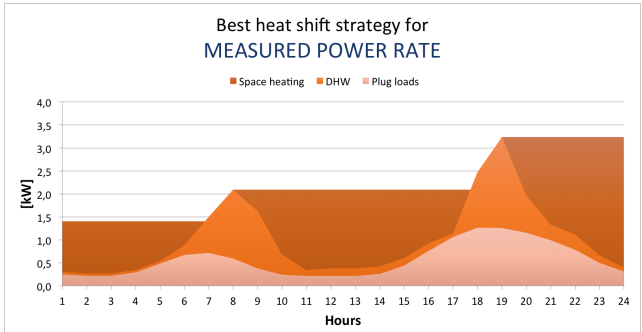

Figure 7: Load shifting strategy of SH with the MP scheme.

house, an electric battery.

Figure 6 illustrates a typical load profile for a residential building where there is no value of timing energy consumption. Note that the load profile is separated between plug loads, DHW loads and SH loads. This load profile is cost-optimal under the ER scheme.

Figure 7 shows how SH load ideally is controlled to minimize costs for the MP scheme. Since there is a penalty for the highest daily peak, the ideal control would be to reduce maximum load down to the highest uncontrollable load. However, since this is unknown at the start of the day, the best strategy is to minimize the controllable load (flatten the load) although this might not be cost-optimal ex-post.

Figure 8 illustrates ideal load shift under the TR scheme. The strategy is to minimize the power outtake above the subscribed limit. This model is good at valuing peak shaving down to the subscribed limit. For all the cases, the cost-optimal subscribed limit is the same with and without performing load shifting as no cases benefit from reducing the subscribed limit to achieve cost savings from load shifting.

Figure 9 shows the ideal load shift under the ToU scheme. Load during the penalty hours is ideally removed completely. This would lead to heating at night and does not guarantee peak shaving of the building load profile; rather, the peak is potentially moved to non-penalty hours and might even lead to an increased peak load of the building. Our assumption of no losses in load shifting is also challenged by this strategy.

\section{Costs under different tariff schemes}

There exists many energy simulation programs that are able to calculate energy cost, e.g. IDA ICE, HOMER and SAM. All these programs can calcu-

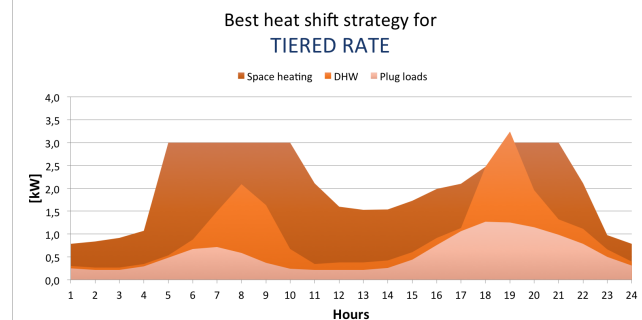

Figure 8: Load shifting strategy of SH with the TR scheme.

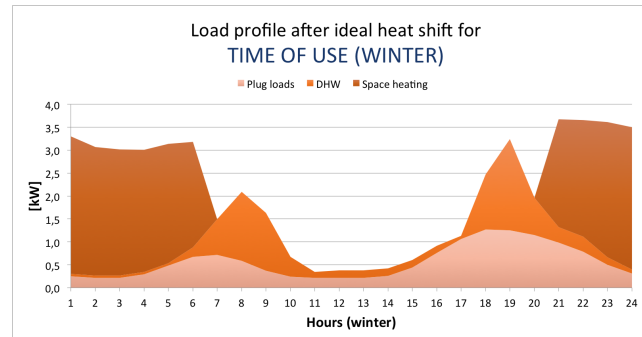

Figure 9: Load shifting strategy of SH with the ToU scheme.

late different types of energy-based rates, but none of them are able to calculate power-based rates. To calculate the price for the MP scheme, the TR scheme and the savings due to load shifting for all tariff schemes, a new algorithm was developed and implemented in Microsoft Excel. The algorithm works as a tool to investigate the effectiveness of different grid tariff schemes to trigger building renovation, installations of energy efficient appliances and control systems, as well as a theoretical SH load shifting within the building.

The Excel program takes the energy demand of the building and the outdoor temperature at the location as inputs from IDA ICE. We then calculate total demand, cost for all tariffs (both with and without load shifting), amount of daily energy use shifted and amount of savings per $\mathrm{kWh}$.

To compare all the 96 different cases, another Excel workbook is importing the results of each case by direct links. The annual demand variations, tariff costs, ideal load shift, load profiles and standard deviation is calculated in this workbook and compared.

\section{Results}

\section{Annual electric energy import}

Annual electric energy import sorted by parameters is displayed in Figure 10. The '60s envelope have significantly higher average import than the cases with TEK17 envelope. The standard deviation between the cases is quite similar.

The ASHP increases the energy efficiency in buildings. The buildings with high heating consumption can save up to $25,000 \mathrm{kWh} /$ year. The standard deviation decreases with ASHP, indicating that the ASHP makes total energy consumption less sensitive to changes in the other parameters. The average electric outtake decreases most in the morning with 


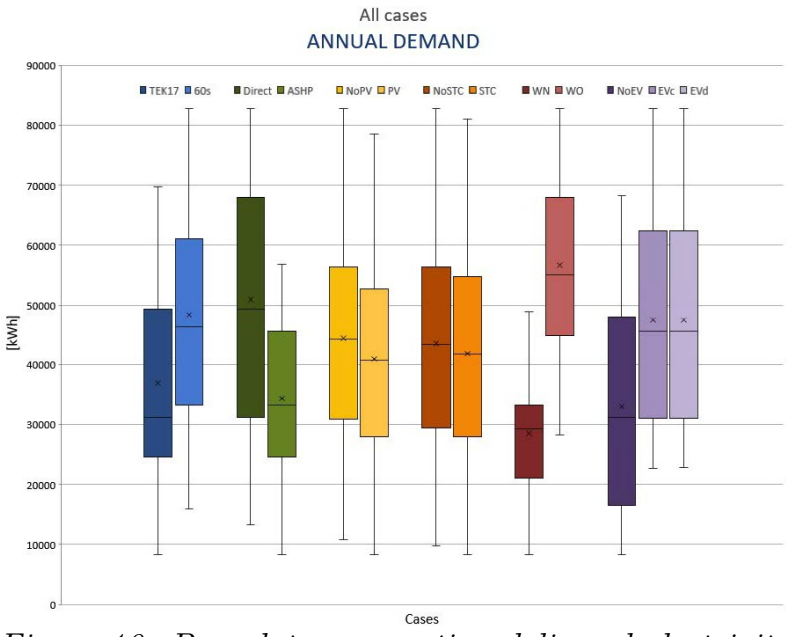

Figure 10: Box plot representing delivered electricity from the grid in all cases keeping one parameter fixed.

ASHP, as there is a large peak on the heating system in the morning due to increased temperature set point.

The PV panels decrease the energy import with about $3,000 \mathrm{kWh} /$ year for cases with high electric consumption. The PV panels decrease the load during the day and most at midday. The morning peak from the building is slightly reduced, but the evening peak is not.

The STC is only affecting the hot water consumption, which does not vary across the cases (independent of our parameters). STC therefore decreases consumption with an equal amount for all cases: 1,718 kWh/year. The largest load reduction with STC happens in the evening when the DHW demand is large and the STC is heating best due to the angle of the collectors.

Like the STC, charging an EV only increases the average electric consumption. With typical EV charging, the evening peak is largely increased. With delayed EV charging, there is a new peak late in the evening and early in the morning, but not as large as for the typical charging.

The largest difference in energy consumption is found between buildings with different window openings. The average electric consumption and standard deviation is significantly larger for OCO cases. This behaviour holds a larger potential for energy savings than performing renovation or changing from direct electric heating to ASHP. The increase in consumption for OCO is largest in the evening when there is already a peak.

\section{Envelope}

Considering renovation of the building envelope, the ER scheme gives the lowest average cost and the TR scheme gives the highest average cost and large standard deviation. Buildings with high energy consumption get especially large costs in the TR scheme com-

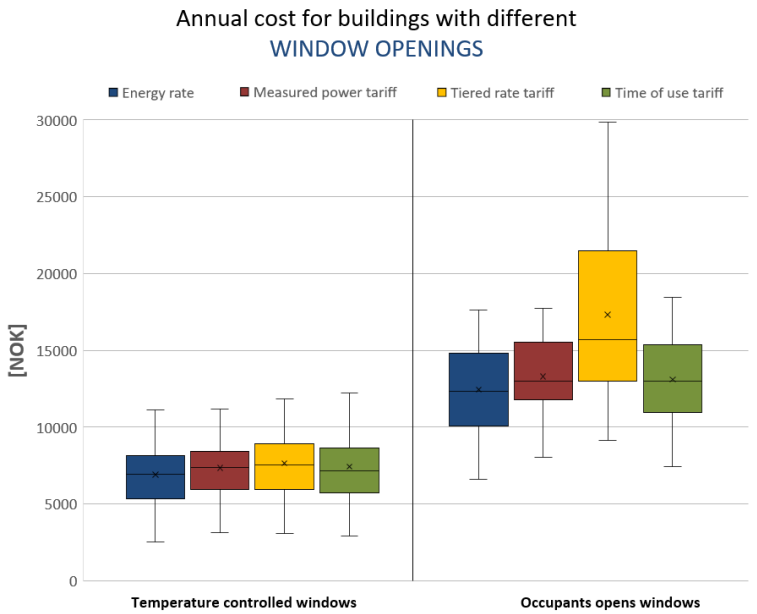

Figure 11: Box plot of the total costs of all schemes with different window openings.

pared to the other schemes. For the '60s envelope, the average cost of the TR scheme is higher also for low demand buildings. For the TEK17 envelope, the price is similar for all of the three new tariff schemes.

\section{Heating systems}

For the electric heating systems, the ER scheme gives the lowest average cost, and the TR scheme has the highest average cost for both heating systems. An ASHP decrease the average costs and the standard deviation for all tariff schemes. Particularly risk of high costs in the TR scheme is reduced with ASHP.

\section{Solar thermal collector}

The impact of STC is small. The TR scheme gives the highest average cost for all cases and a large standard deviation. The MP scheme gives the lowest cost when not considering the ER scheme.

\section{Solar PV}

With PV panels, the total average cost is reduced. The reduction is largest for the buildings that have a high cost due to high consumption without PV because more of the produced energy is consumed locally (without storage). The cases have excess energy between $974 \mathrm{kWh} /$ year and 2,733 kWh/year with an average of $1,751 \mathrm{kWh} /$ year, i.e. more than half of the production is not consumed immediately and on-site for some cases. Without considering the ER scheme, the MP scheme gives the lowest median. The ToU scheme has a median cost slightly higher than for the MP scheme. The TR scheme has high average cost, median cost and standard deviation compared to the other schemes.

\section{Window openings}

The box plot in Figure 11 shows a large difference in average cost with TCO and OCO window opening strategies. With TCO, the ToU scheme has the largest standard deviation, and the MP scheme has the smallest. The TR scheme has the highest average cost in both cases. With OCO, the average cost and standard deviation with the TR scheme is significantly higher than for the other schemes. 


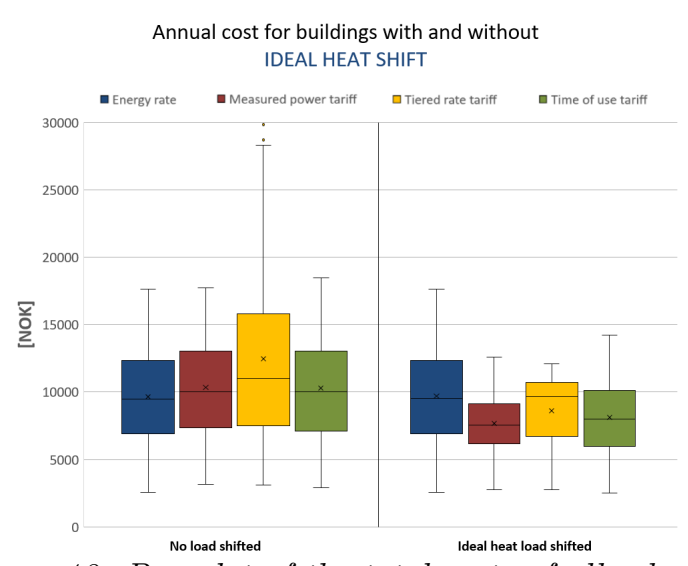

Figure 12: Box plot of the total costs of all schemes with and without load shifting.

\section{Electric vehicle charging}

Delayed EV charging results in a lower average cost than typical EV charging. The average cost for the TR scheme is reduced the most with delayed charging, but the TR scheme still gives the highest average cost for both kinds of charging profiles. The MP scheme gives the lowest average price for both profiles without considering the ER scheme. The ToU scheme has a median equal to the MP scheme but a larger standard variation.

\section{Heat load shifting}

Figure 12 presents the cost for cases with and without ideal load shift. All tariff schemes except the ER scheme give reduced average and median costs with load shifting. Cases with high cost without load shift can achieve large savings in cost with SH load shift, while the cases with low cost without load shift have small savings with shifting. Without shifting, the ER scheme gives the lowest cost, but it is the tariff scheme with highest cost with shifting. The TR scheme gives the largest average cost reduction and largest savings per $\mathrm{SH}$ load shifted (1 NOK/kWh), but is still the most expensive (except for the ER scheme) with load shift. The MP scheme gives the lowest cost with load shifting and the second largest savings per SH load shifted on average $(0.3-1.1 \mathrm{NOK} / \mathrm{kWh})$. The ToU scheme offer rather small savings per $\mathrm{SH}$ load shifted compared to the MP and the TR scheme $(0.2 \mathrm{NOK} / \mathrm{kWh})$. The maximum daily energy that is needed to shift to obtain the highest possible cost reduction is around $50 \mathrm{kWh}$ for the MP and TR scheme and more than double for the ToU scheme $(>100$ $\mathrm{kWh})$.

\section{Discussion}

The largest economical incentive to perform energy efficiency measures in a building depends on how the improvement changes the load profile. If lowering energy use is the most important, the energy based tariffs (ER and ToU) gives the largest incentive. If peak load reduction is important, the TR tariff gives the largest incentive (largest savings with certainty) while the MP tariff offers the cheapest bill with SH load shifting.

The ToU tariff has the lowest annual cost for most cases without load shift and the fewest cases with highest cost. The ToU tariff has the largest amount of potential load shift. This creates a large potential for cost savings, but large flexibility, e.g. through storage, would be necessary for the customers to obtain the maximum cost reduction with load shift. The ideal cost saving is therefore less achievable with a ToU tariff and losses will be important to consider. The ToU tariff encourages shift only in the hours with assumed stress on the grid capacity. However, there is a potential that too much load is moved to low cost hours, thus only moving the peak load problem.

The TR tariff is reliable and will give large savings with high certainty per kWh shifted. The TR tariff also gives the largest potential for cost reduction with improved building physics and/or load shifting. High cost savings per $\mathrm{kWh}$ provide large incentive to install a small storage. However, the TR tariff creates a higher average cost than today's ER tariff. This means that the TR tariff might not ensure a fair cost division if rates are poorly determined. The tariff has a high administration cost since all customers must be considered according to their subscription, which should be offset by the savings from triggering load shifting.

The MP tariff has the lowest cost for the cases with ideal load shift, but the average cost reduction obtained when introducing load shift is less than for the TR tariff. The MP tariff has the smallest possibility of cost savings through daily load shift. It also has significant uncertainty related to when the highest daily peak will occur. The MP tariff has potential for the lowest total cost with load shift, and the highest potential for cost reduction with delayed charging of EV.

Incentives provided with new grid tariffs need to be easy to understand and react to if the desired effect is to be achieved. The easiest model to understand is the ToU tariff, as it only consist of energy cost (kWh) and timing of energy use. The ToU is also the easiest model to predict, plan and react to. Both the MP and the TR tariff might be hard to fully understand by customers. Overuse is not easy to predict with the TR tariff, but it is potentially easy to react to in the moment of overuse through signaling. The MP tariff is difficult to predict, and it is not easy to react to as the maximum future peak load is unknown.

\section{Conclusion}

Implementation of any of the suggested power-based tariffs will increase costs for customers whom continue to use electricity with an unchanged consumption pattern. Changing strategy for window openings is affecting total consumption and cost the most of our 
considered building parameters, followed by changing electric heating system and performing building renovation. Increased energy efficiency reduce the cost, but only with SH load shift can the tariff schemes potentially reach an annual cost lower than for the ER tariff. Increasing energy efficiency generally decreases the potential to save costs through load shifting because less energy is used, however, there are always additional savings of performing load shifting in all 96 cases under all pricing schemes except the ER tariff. Note that this is without considering losses of performing load shifting.

The MP tariff incentivizes least load shifting but gives the lowest cost for most cases. The TR tariff has the largest cost saving per $\mathrm{kWh}$ of load shifted and incentivizes the second least load shifting, but result in the highest annual cost for most cases. The ToU tariff incentivizes the largest amount of load shifting, but has the smallest cost saving per kWh. Today's ER tariff provide most incentive for increased energy efficiency.

Load shifting might occur partly at the expense of higher total energy consumption when considering losses. Further research is needed to understand the cost effect of considering losses in load shifting and considering other loads than SH to be shifted. Further research is also needed to determine tariff rates taking into account the probability of how many (and how much) customers are likely to shift their load and contribute to a decrease in income for the grid companies. Comparing the savings in peaking infrastructure with the total customer savings will be needed to better understand how to determine tariff rates.

\section{Acknowledgment}

We wish to thank Vilde C. Hagen for supplying the basis for the reference model used in the IDA ICE simulation. We also thank Hafslund Nett by Ragnar Ulsund, who has contributed with information about the grid in the Oslo area. We acknowledge FME ZEN - The Research Centre on Zero Emission Neighbourhoods in Smart Cities hosted by NTNU and SINTEF. The centre is funded by the Research Council of Norway through the scheme of the Centres for Environment-friendly Energy Research (FME) and centre partners.

\section{References}

AboGaleela, M., M. El-Sobki, and M. El-Marsafawy (2012). A two level optimal DSM load shifting formulation using genetics algorithm case study: Residential loads. In Power Engineering Society Conference and Exposition in Africa (PowerAfrica), 2012 IEEE, pp. 1-7. IEEE.

De Groote, M. and M. Fabbri (2016). Smart buildings in a decarbonised energy system. Buildings Performance Institute Europe, BPIE, Brussels, Belgium.
DiBK (2017). Byggteknisk forskrift (TEK17) - Direktoratet for Byggkvalitet.

EU (2011). European Commission: A Roadmap for Moving to a Competitive Low Carbon Economy in 2050. European Commission, Brussel.

Eurelectric (2014). Making your sense of electricity bill.

Faruqui, A., D. Harris, and R. Hledik (2010). Unlocking the $€ 53$ billion savings from smart meters in the EU: How increasing the adoption of dynamic tariffs could make or break the EUs smart grid investment. Energy Policy 38(10), 6222-6231.

Faruqui, A. and S. Sergici (2010). Household response to dynamic pricing of electricity: a survey of 15 experiments. Journal of regulatory Economics 38(2), 193-225.

Fridgen, G., M. Kahlen, W. Ketter, A. Rieger, and M. Thimmel (2018). One rate does not fit all: An empirical analysis of electricity tariffs for residential microgrids. Applied Energy 210, 800-814.

Gottwalt, S., W. Ketter, C. Block, J. Collins, and C. Weinhardt (2011). Demand side management a simulation of household behavior under variable prices. Energy policy 39(12), 8163-8174.

Hagen, V. C. (2018). Robustness Assessment Methods to Identify Robust High-Performance Building Designs. Master thesis, Norwegian University of Science and Technology.

Hansen, H., T. Jonassen, K. Løchen, and V. Mook (2017). Høringsdokument nr 5-2017: Forslag til endring i forskrift om kontroll av nettvirksomhet. Norges vassdrags- og energidirektorat.

Ipakchi, A. and F. Albuyeh (2009). Grid of the future. IEEE power and energy magazine 7(2), 52-62.

Lopes, J. A. P., F. J. Soares, and P. M. R. Almeida (2011). Integration of electric vehicles in the electric power system. Proceedings of the IEEE 99(1), 168-183.

Palensky, P. and D. Dietrich (2011). Demand side management: Demand response, intelligent energy systems, and smart loads. IEEE transactions on industrial informatics 7(3), 381-388.

Schreiber, M., M. E. Wainstein, P. Hochloff, and R. Dargaville (2015). Flexible electricity tariffs: Power and energy price signals designed for a smarter grid. Energy 93, 2568-2581. 